\title{
The subjectivity of the personality of learners as a response to the challenges of modern times
}

\author{
Arina Shvetsova ${ }^{1, *}$, Maria Kuprina ${ }^{1}$, Lyudmila Rumyantseva ${ }^{1}$ \\ ${ }^{1}$ Sakhalin state University, Lenin street, 290, build. 6, 693008, Yuzhno-Sakhalinsk, Russia
}

\begin{abstract}
Justification of the objectives of the study: the article discusses issues related to the present, faced by students and future professionals, as well as teachers and psychologists. Subjectivity is an integrative, complex characteristic of personality. The purpose of this study: to consider the concept of "subjectivity" as a qualitative characteristic of a personality that opens up the possibility of adapting to the challenges of our time. Identify points of underdevelopment for the prospects of psychological activity in this area. Research methods: Components of subjectivity determined the choice of methods. Accordingly, to study the level of subjective control localization, we used the J. Rotter test questionnaire, the Everett L. Shostrom questionnaire to determine personal orientations, and the diagnosis of reflexivity to study the level of development of emotional intelligence. A.V Karpova and the Toronto alexithymia scale. Research results: most students tend to focus on a structure set from the outside, focused on external, often alien personality factors, which does not contribute to the development of subjectivity, does not form responsible for the learning outcome Main conclusions. At the student age, direct directed psychocorrectional work on the development of the components of subjectivity is possible and necessary. For this, it is necessary: the inclusion in the process of goal-setting and planning of various types of activities; the creation of situations of choice and self-determination, social and professional tests. Such efforts will allow the formation of a modern personality that can meet the challenges of our time.
\end{abstract}

\section{Introduction}

Discussion of issues related to the challenges of our time is increasingly common in science and practice. This topic is devoted to conferences in the psycho-pedagogical sphere, in socio-philosophical, in economic and others. Among the most pressing problems are:1) Redundancy of information and its flows, most recently the problem was in finding the necessary information, now the person needs protection and filters of information, in the ability to select the necessary and reliable;2) Digitalization of communication, the consequences of such a change in the formation of the psyche of the child at different age stages is now actively predicted by psychologists, and the most frequent forecast is autism and social infantilism;3) Mental hedonism, so conditionally we called the desire of man to avoid disturbing information requiring tension and inclusion in new social activity; 4) high

\footnotetext{
*Corresponding author: arina@ens-tech.ru
} 
migration activity; 5) Changing the importance of the institution of the family and many others.

\section{Purpose of the study}

To consider the concept of "subjectivity" as a qualitative characteristic of personality, opening the possibility to adapt to the challenges of modern times. Study the level of development of the components of the subject in students. To identify points of underdevelopment, for prospects of psychological activity in this area.

For the psycho-pedagogical sphere, the challenges of our time are, first of all, issues related to the education and development of students in the educational system. Questions of their readiness to act in a rapidly renewing world, to build their lives and to be successful. The relevance of this topic is due to the loss of the usefulness of traditional transfer of experience and a specific set of knowledge. The world is changing so quickly and significantly that the experience of older generations is becoming irrelevant, and the set of competencies that a modern person should possess is constantly increasing. It is about the psycho-pedagogical tasks of building such complex personal characteristics, which will allow the person to be stable and clearly aware of his goals and life strategies, at the same time to be flexible-adaptive and to understand what changes are necessary, to independently build the trajectory of personal and professional development.

Subjectivity in our view, is one of those complex characteristics of personality, the formation of which gives the key to successful integration into modernity. The view on the process of formation and development of man through his subject properties was first considered in domestic psychology within the framework of the subject-activity approach, in connection with the concept of life path. The concept of subjectivity is used in their works Verbitsky A.A. [1]., Serikov V. V. [2], Zeer E. F., Meshkova I. V. [3], etc., most often mentioning the following signs of subjectivity: personality traits and the basis of individuality; activity; self-regulation; a manifestation in communication and activity; changing the world and yourself; creativity with his life. In opinion V. V. Serikov, «subjectivity in educational activity is a line of behavior, expressed in independence manifested in the chosen strategy of the solution, reflection, self-assessment of the course and result of the decision aimed at self-change of the subject».

In the concept of personality-oriented education, subjectivity is considered based on the components of the manifestation of personality in a trinity of aspects: individuality, interindividual (because personality is created and manifested in a group) and personal contributions to other people through activities [4], [5].

V.I. Panov, A.V. Kaptshov, E.I. Kolesnikova conducted a formative experiment on the development of subjectivity and its components in students relying on didactic and psycho didactic aspects, showed its connection with the value sphere of personality [6].

M.V. Chvetkova includes the concept of "subjectivity" - activity, reflection, freedom of choice, uniqueness, acceptance of another, self-development. In her studies, she considers the function of reflection of consciousness as the most significant component of subjectivity, capable of structuring goal-setting in objective activity and the system of interactions [7].

Increasing subjectivity with age allows a person to overcome the total dependence of a person on external conditions, to move towards self-determination, independence, and independence from the environment and the environment as a whole. The general direction of this development is that the child gradually turns from a being subordinate to external influences, into a subject capable of acting independently based on consciously set goals and accepted intentions. 
Today, active work continues on the creation and development in psychological and pedagogical science and practice of the means and conditions for the formation of the subjective position of students.

R. M. Granina defines the formation of the subjective position as a holistic, dynamic process of development and self-development of the student, aimed at revealing his personal qualities and properties, self-determination of his personality in the educational and professional space. [8].

Looking at the structural characteristics of subjectivity you can refer to the works of N.O. Schuplenkov. In his opinion, the subjectivity of a person, acting as a systemic quality of the personality, integrating into itself such characteristics as activity, independence, responsibility, reflectivity, constructive interaction with the environment, the ability to selfdevelopment, is closely related to the foundations of the integral personality of the individual [9].

The presence of expressed subject position, including professional position, contributes to the actualization of motivation and need a sphere of personality and an increase of its general activity. Due to the realization of the subject-professional position, the internal potential of the person is revealed, ensuring the possibility of self-measurement and subsequent personal and professional self-realization and self-projection. Subjectivity as a systemic quality of personality acts as a condition of formation of a future professional, as well as a person with an active life position.

A.A. Dargan Considers the concept of social subjectivity as qualities of the person, which determine its ability to exercise conscious independent choice in the field of social relations, to build a value attitude to the most important aspects of social life and to plan its life trajectory [10]. A similar view of V.V. Aliyev, he considers two main criteria of manifestation of the social subject of young people: 1) possession of the subject socially conditioned opportunities to social activity; 2) the ability of the entity to carry out social activities independently [11].

Most authors view subjectivity as an integrative characteristic of the individual, reflecting its active-selective, proactive-responsible transformation of relations to themselves, to activities, to people, to peace and life in general. In the formation of subjectivity, nested processes of self-determination, self-regulation, self-realization, selfidentification, self-projection are identified. Activity, initiative, and focus are particularly stressed - as leading characteristics of the subject position of the individual.

A.B. Kholmogorova and E.N. Klimenkov revealed the relationship of the expressed subject position and empathetic abilities, which confirms our idea that the subjectivity of the person is a complex and key characteristic of the person, determining the direction of psychologic-pedagogical efforts [12].

As we can see, the concept of "subjectivity" is defined through a set of personality characteristics that it integrates - activity, reflexivity, awareness of value orientations, purpose, responsibility, with some possible options in different authors. Accordingly, the level of formation of each of these personality characteristics can be considered as a factor in the development of the subject as a whole. Logically, for school periods of education, the importance of such components of subjectivity as activity and reflexivity, adequate to age development, is stressed. More complex components such as targeting, self-regulation, and others are possible to diagnose and target form from the high school period, so student age will be most favorable for their development.

N. V. Matyash, Yu. V. Ereshchenko, I. V. Drobyshevsky note that in youth almost finally a system of ideas of a person about himself is formed, some generic idea of himself is formed, which, regardless of whether it is true or not, represents a psychological reality affecting a behavior that generates certain experiences. All this is determined by the strengthening of personal control, self-government, the "new stage" of intelligence development, the 
"discovery" of its internal world. There is a formation of resilient management behavior in various stressful situations, which in turn in conditions of educational and professional activity can contribute to the improvement of the physical and mental health of students, successful self-certification [13].

Generalizing the considered researches, it is possible to claim that most of the authors defining subjectivity of the personality and characterizing the process of her formation have components - goal-setting, focus, or commitment. It should also be stressed that in most approaches to the processes of targeting and subjectivity in psycho-pedagogical theory and practice, their development is expected through inclusion in the general education process, provided that activating and innovative pedagogical technologies are used. Accordingly, it is the search for conditions and technologies that contribute to the effective formation of the subject matter and its components that are the main subject of discourse in this matter.

It is important to emphasize that the subjectivity, in the opinion of most authors, is the quality acquired, formed and manifested inactivity, communication, and self-awareness. In other words, activities at every stage of development should be shaped and integrated. According to Dyakov S.I., it is impossible to ensure the optimal development of educational space in the university without subject participation of students, they are full subjects of educational space [14].

The study of the level of subjectivity among university students is indicative of our study, as youth age is resulting in the entire period of schooling and the student environment constitutes the most responsible and committed part of young people. Consequently, it is possible to identify the components of subjectivity sufficiently formed during the school period by modern teaching methods.

In our view, the problem of measuring subjectivity today exists and has several directions. First, the characteristics of subjectivity differ in different age categories. In younger schoolchildren it is a formed subject attitude to educational activity, in teenagers the appearance and manifestation of specific personal characteristics related to attitude to peace and self, in youth - attitude to future professional activity and its choice as such. Accordingly, for each age group, a certain set of diagnostics is meant to measure the subjectivity, including both specific, leading activity-related and determined by it, and general, age-specific modified personality characteristics. Secondly, the question arises as to which characteristics are necessary and sufficiently measured and based on which it is reliable to conclude the established subjectivity of the individual.

Modern educational space is organized in such a way that it makes it impossible to teach by coercion, on the one hand, and, on the other hand, requires an active position from the student. The vast amount of information in the public domain also raises the question of choice, which depends on motivation and the ability to set a goal. The formed need to acquire knowledge and skills currently depends entirely on certain qualities of the person, the set of which determines the subjectivity of the person, and in turn makes it oriented, adaptive, successful in the activity.

\section{Materials and methods}

The measurement of the subjectivity of students studying at the university is possible from research and analysis of the following personal characteristics: subjective localization of control, level of self-actualization of the person, using the questionnaire of personal orientations Everett L. Shostrom (Personal Orientation Inventory, POI, 1963); Characteristics of self-organization; Ability to reflex and level of reflexivity development, ability in the verbalization of own emotional states as an important component of emotional intelligence, indicating the level of its development. 
Subjective localization of control, namely high indicators of the internality of control locus, seems to us an important characteristic of personality subjectivity, as taking responsibility for events of own life is coupled with good adaptation to what is happening, satisfaction with relations, including close ones, higher requirements to themselves and results of own activity, high search activity (So relevant in today 's world and related to the need and ability to constantly learn). Also, the internal locus of control gives the subject an idea of the manageability of the events and successes of his own life, which makes him more confident, calm, and emotionally attractive to others.

To study the level of internality we used the test-questionnaire subjective localization of control - modification of the scale 1-E J. Rotter.

\section{Results}

The study was attended by 200 students of the University of Sakhalin State University, 68 young male and 132 female, age group 18-21 years, pedagogical and psycho-pedagogical directions. Quantitative and qualitative analysis of LSC (Level of Subjective Control) indicators by seven scales when comparing the results of the obtained "profile of UCS indicators" with the norm showed the following results:

Table 1. Indicators LSC.

\begin{tabular}{|c|c|}
\hline $\begin{array}{c}\text { Deviation to the right }(\mathbf{> 5 , 5 s n}) \\
\text { Internal type of control (LSC) }\end{array}$ & $\begin{array}{c}\text { Deviation to the left from the norm }(<\mathbf{5 , 5} \\
\text { sn) external type LSC }\end{array}$ \\
\hline $87 \%$ & $13 \%$ \\
\hline
\end{tabular}

The findings show that most students believe that important events in their lives are the result of their actions, that these events are manageable, and thus they feel their own responsibility for these events and for how their lives are formed as a whole.

The most promising levels of reflexivity and Alexithymia of the subject appear to us in terms of research of subjectivity. Particularly interesting can be such characteristics of Alexithymia as weak ability to symbolize, fantasize (Including representing performance, representing yourself in a particular social role, etc.), Difficult orientation in reflecting the experiences, sensations, and sensual and emotional reactions of others (As a consequence of weak reflection of success-failure of own activity, a total deficit of external expression of emotions and bodily sensations), Orientation towards events from outside (as a consequence of the lack of search for its comfortable emotional state inactivity). The Toronto Alexithymia Scale chosen by us for the study, adapted at the V.M. Behterev Institute, is indicative of the level of development of emotional intelligence.

Table 2. Alexithymia indicators.

\begin{tabular}{|c|c|c|}
\hline Normal Level & Intermediate & $\begin{array}{c}\text { Indicators corresponding to } \\
\text { explicit Alexithymia }\end{array}$ \\
\hline $73 \%$ & $18 \%$ & $9 \%$ \\
\hline
\end{tabular}

For the completeness of the study, we used the technique of diagnostics of the reflexivity of A.B. Karpov [15]. The diagnosis seems particularly interesting as it examines all reflexivity properties implying its situational, retrospective, and forward-looking focus. The forward-looking and retrospective focus is related to the ability to plan activities. And situational is connected with characteristics of emotional intelligence and allows them to quickly make decisions in the current real situation. 
An interesting indicator is an observation that the indicators of apparent alexithymia were inherent exclusively in male, intermediate degrees are presented by the majority of male respondents.

The following results were obtained using A.B. Karpov reflexivity diagnostics.

Table 3. Reflexivity indicators.

\begin{tabular}{|c|c|c|}
\hline $\begin{array}{c}\text { High level } \\
\text { development of reflexivity }\end{array}$ & $\begin{array}{c}\text { Average level } \\
\text { development of reflexivity }\end{array}$ & $\begin{array}{c}\text { Low level } \\
\text { development of reflexivity }\end{array}$ \\
\hline $4 \%$ & $88 \%$ & $8 \%$ \\
\hline
\end{tabular}

The concept of self-actualization is interpreted broadly and has long gone beyond the understanding described in A. Maslow 's concept. Within the framework of this study, we consider self-actualization as a need for self-development, determined by value settings. This interpretation allows us to include self-actualization as a characteristic of the measurement of personality subjectivity.

Interesting results of diagnostics of self-actualization of personality obtained using the questionnaire of personal orientations Everett L. Shostrom (Personal Orientation Inventory, POI, 1963) are presented. The methodology includes 100 paired statements, of which one must be selected during the survey process, distributed over 11 scales, and also involves the calculation of the "total self-actualization indicator," determined in percent.

Table 4. General indicator of self-updating.

\begin{tabular}{|c|c|c|c|}
\hline Technique indicators & $40-49 \%$ & $50-59 \%$ & $60-70 \%$ \\
\hline $\begin{array}{c}\text { Percentage } \\
\text { distribution } \\
\text { of student sample }\end{array}$ & $26 \%$ & $39 \%$ & $35 \%$ \\
\hline
\end{tabular}

Table 5. Orientation in time.

\begin{tabular}{|c|c|c|c|c|c|c|}
\hline $\begin{array}{c}\text { Technique } \\
\text { indicators }\end{array}$ & $30 \%$ & $40 \%$ & $50 \%$ & $60 \%$ & $70 \%$ & $80 \%$ \\
\hline $\begin{array}{c}\text { Percentage } \\
\text { distribution of } \\
\text { student sample }\end{array}$ & $4 \%$ & $6 \%$ & $23 \%$ & $14 \%$ & $31 \%$ & $22 \%$ \\
\hline
\end{tabular}

The spread of indicators on the time scale shows how different the ability of respondents to live here and now, the real moment, without trying to "run away" to the past or spending life waiting for the future. Most likely, this skill is formed chaotic or is a consequence of family education. The influence of educational organizations is probably slightly represented.

The attitude towards time is reflected in the indicators obtained through the study using the Self-Organization Questionnaire Test.

The third diagnostic unit is associated with the self-organization of the personality. The subjectivity of the individual manifests itself in the ability to manage its activities, including through external means. The self-organization of the individual manifests itself in activities, is related to the ability to plan and set goals, manage time, in turn carefully planning and prioritizing it. 
Table 6. Activity self-organization.

\begin{tabular}{|c|c|c|}
\hline $\begin{array}{c}\text { High level } \\
\text { activity self-organization }\end{array}$ & $\begin{array}{c}\text { Average level } \\
\text { activity self-organization }\end{array}$ & $\begin{array}{c}\text { Low level } \\
\text { activity self-organization }\end{array}$ \\
\hline $0 \%$ & $28 \%$ & $72 \%$ \\
\hline
\end{tabular}

The high total level was not common to the students of the sample, which indicates a lack of ability to plan their activities, to see the goal, to persevere in its achievement. An interesting observation is a fact that higher indicators were revealed in students of the department of physical culture and sports whose sports life is coupled with the ability to set and clearly see the goal. Low total scores characterize a person who is not used to daily planning of his activity and to making will efforts to implement plans, but it is characteristic to quickly change to new activities, as the absence of his own structure allows to "not get stuck" neither on previous activities nor on current sensations.

It is regrettable to recognize that learning in the existing educational system teaches the majority of students to focus on the structure set from the outside, oriented towards external, often alien factors, which does not contribute to the development of the subject matter, does not form responsible for the result of learning. Project activities (currently, despite efforts, are poorly represented in a modern school and in higher education) as one of the ways to overcome weak self-organization of activities.

\section{Discussion}

The aggregate data on the results of the methods make it possible to obtain a general idea of the level of the subjectivity of the person, as well as to draw attention to the points preventing the formation of subjectivity and to identify ways of corrective work. It should be recognized that the development of the subject matter process is long-term and multi-stage, as well as largely determined by the subjective situation of the child 's development and biological factors. Its multi-stage and long-term duration is predetermined by age stages of personal neoplasms formation through the mastering of leading types of activities. Subjectivity is predetermined by the situation of family education, the quality, and variety of educational programs, as well as genetic moments and moments associated with the peculiarities of individual biological development. The subjective situation of development is not considered in detail within the framework of this article, but it should be taken into account in the construction of individual educational routes or in the development of corrective programs.

\section{Conclusions}

In our opinion, in student age direct, directed psycho-correction work on the development of components of subjectivity is possible and necessary. These can be social training on the development of targeting, strategies of life-building and life-creation, personal growth, and others. Corrective work should be based on the results of the preliminary diagnostic examination, according to which it is useful to form training groups or plan individual work. In order to develop the subject matter of the student, it is necessary to include in the process of targeting and planning various types of activities; Creation of situations of choice and selfdetermination, social and professional samples; Involvement of students in the analysis of their own and collective activities, organization of reflection. Such efforts will create a modern personality capable of meeting the challenges of modern times. 


\section{References}

1. A.A. Verbitsky, The Education and science journal 6, 5-18 (2012) https://doi.org/10.17853/1994-5639-2012-6-5-18

2. V.V. Serikov, The Education and Science Journal 2, 313 (2012) DOI: https://doi.org/10.17853/1994-5639-2012-2-3-13

3. E.F. Zeer, I.V. Meshkova, Education and Science Journal 9, 78-89 (2012) DOI: https://doi.org/10.17853/1994-5639-2012-9-78-89

4. A.A. Verbitsky, Education and Science Journal 6, 5-18 (2012) DOI: https://doi.org/10.17853/1994-5639-2012-6-5-18

5. T.V. Smoleusova, Journal of Novosibirsk State Pedagogical University 6, 7-16 (2016) DOI: https://doi.org/10.15293/2226-3365.1606.01

6. M.V. Tsvetkova, Psychology and Psychotechnics 2, 22-29 (2018) DOI: https://doi.org/10.7256/2454-0722.2018.2.21440

7. V.I. Panov, A.V. Kaptsov, E.I. Kolesnikov, Pedagogy and Education 4, 125-135 (2019) DOI: https://doi.org/10.7256/2454-0676.2019.4.31093

8. R.M. Garanina, Alma Mater (Journal of Higher School) 8, 75-82 (2018) DOI: https://doi.org/10.24411/2224-0772-2019-10001

9. N.O. Schuplenkov, O.V. Schuplenkov, Psychologist 9, 51-82 (2013) DOI: https://doi.org/10.7256/2306-0425.2013.9.10671

10. A.A. Dargan, Philosophy and modernity 2, 82-94 (2019) DOI: https://doi.org/10.17805/zpu.2019.2.7

11. V.V. Aliyev, Knowledge. Understanding. Ability 1, 152-161 (2015) DOI: 10.17805/zpu.2015.1.14

12. A.B. Kholmogorova, E.N. Klimenkova, Advisory psychology and psychotherapy 25(2), 75-93 (2017) DOI: https://doi.org/10.17759/cpp.2017250205

13. N.V. Matyash, YuV. Ereshchenko, I.V. Drobyshevsky, Academic notes of Transbaikal State University. Series. Pedagogical sciences 12(2), 66-74 (2017) DOI: https://doi.org/10.21209/2542-0089-2017-12-2-66-74

14. S.I. Dyakov, The Education and science journal 6, 97-109 (2016) https://doi.org/10.17853/1994-5639-2016-6-97-109

15. A.V. Karpov, E.V. Karpova, Experimental Psychology 9(4), 59-67 (2016) DOI: https://doi.org/10.17759/exppsy.2016090406 